\title{
PENGARUH PEMANFAATAN LIMBAH TERAK SEBAGAI BAHAN PENGGANTI AGREGAT HALUS PADA CAMPURAN BETON TERHADAP KUAT TARIK.
}

\author{
Siti Nur Slaraswati ${ }^{1}$, Anis Rahmawati ${ }^{2}$, Ida Nugroho Saputro ${ }^{3}$ \\ Pendidikan Teknik Bangunan, Universitas Sebelas Maret \\ e-mail: sitinurslaraswati17@gmail.com
}

\begin{abstract}
Abstrak: Tujuan penelitian ini adalah, (1) mengetahui pengaruh terak sebagai pengganti pasir dengan variasi $0 \%, 20 \%, 40 \%, 60 \%$, 80\%, dan $100 \%$ terhadap kuat tarik beton dengan metode perbandingan 1:2:3, (2) mengetahui apakah berat jenis beton yang dihasilkan masuk dalam kategori berat jenis beton normal, (3) mengetahui besar kuat tarik optimal beton yang dihasilkan dari penggantian terak sebagai pasir dengan variasi $0 \%, 20 \%, 40 \%$, 60\%, 80\%, dan $100 \%$ dengan metode perbandingan 1:2:3. Penelitian ini menggunakan metode kuantitatif korelasional. Variabel yang mempengaruhi dalam penelitian ini adalah (1) variabel terikat: kuat tarik, (2) variabel bebas: persentase terak sebagai pengganti agregat halus dengan variasi $0 \%, 20 \%, 40 \%, 60 \%, 80 \%, 100 \%$ dari volume beton dengan perbandingan 1:2:3. Berdasarkan hasil penelitian disimpulkan bahwa, (1) tidak ada pengaruh antara variasi penggantian terak sebagai agregat halus terhadap kuat tarik beton atau penggantian terak sebagai agregat halus tidak berpengaruh secara signifikan terhadap kuat tarik beton, (2) hasil pengujian berat jenis beton menunjukan variasi penggantian terak $0 \%, 20 \%, 40 \%, 60 \%, 80 \%, 100 \%$ telah mencapai berat jenis beton normal yaitu $2200 \mathrm{~kg} / \mathrm{m}^{3}-2500 \mathrm{~kg} / \mathrm{m}^{3}$. (SNI 03-2834-2000), (3) persentase terak optimal sebagai pengganti agregat halus yang menghasilkan kuat tarik beton maksimal terdapat pada persentase penggantian terak 80\% yaitu sebesar 5,700 MPa.
\end{abstract}

Kata Kunci : beton, terak, kuat tarik, berat jenis

\footnotetext{
${ }^{1}$ Mahasiswa Program Studi Pendidikan Teknik Bangunan FKIP UNS

2 Pembimbing I Anis Rahmawati, S.T., M.T.

3 Pembimbing II Ida Nugroho Saputro, S.T., M.Eng.
} 


\title{
THE EFFECT OF WASTE SLAG AS FINE AGGREGATE ON THE CONCRETE MIX TOWARD THE TENSILE STRENGTH AND THE SPECIFIC GRAVITY.
}

\author{
Siti Nur Slaraswati ${ }^{1}$, Anis Rahmawati ${ }^{2}$, Ida Nugroho Saputro ${ }^{3}$ \\ Pendidikan Teknik Bangunan, Universitas Sebelas Maret \\ e-mail: sitinurslaraswati17@gmail.com
}

The objectives of this research were, (1) to observe the effect of utilization waste slag as the substitues of fine aggregate with variation $0 \%, 20 \%, 40 \%, 60 \%$, $80 \%$, and $100 \%$ toward the tensile strength with the equivalent method 1:2:3, (2) to observe was the resulting specific gravity resulted fall into the category of normal concrete, (3) to observe the optimum tensile strength of concrete with slag as fine aggregate with variation $0 \%, 20 \%, 40 \%, 60 \%, 80 \%$, and $100 \%$ with the equivalent method 1:2:3. This research used correlational method. Variables in the study were (1) depedent variable: tensile strength, (2) independent variable: percentage of slag with the fine aggregate replacement with variation $0 \%, 20 \%, 40 \%, 60 \%$, $80 \%$, and $100 \%$ of the concrete volume with the equivalent method 1:2:3. Based on the result of the study concluded that, (1) there was no effect with replacement of slag as fine aggregate toward tensile strength of the concrete or the replacement of slag as fine aggregate has no significant effect toward tensile strength of the concrete, (2) the specific gravity of concrete with variation replacement of $0 \%, 20 \%$, $40 \%, 60 \%, 80 \%$, and $100 \%$ include categories of normal concrete $2200 \mathrm{~kg} / \mathrm{m}^{3}$ $2500 \mathrm{~kg} / \mathrm{m}^{3}$. (SNI 03-2834-2000) (3) the percentage of optimum slag as the replacement of fine aggregate toward tensile strength of the concrete was percentage $80 \%$ generate tensile strength of 5,700 MPa.

Keywords : concrete, slag, tensile strength, specific gravity.

\footnotetext{
${ }^{1}$ Mahasiswa Program Studi Pendidikan Teknik Bangunan FKIP UNS

2 Pembimbing I Anis Rahmawati, S.T., M.T.

${ }^{3}$ Pembimbing II Ida Nugroho Saputro, S.T., M.Eng.
} 


\section{PENDAHULUAN}

Beton merupakan salah satu bahan bangunan yang sangat populer hingga saat ini, beton telah dipakai secara luas sebagai bahan konstruksi baik pada konstruksi skala kecil, menengah, hingga konstruksi besar seperti bangunan-bangunan gedung yang tinggi, hingga sarana transportasi. "Beton adalah campuran antara semen Portland atau semen hidraulik yang lain, agregat halus, agregat kasar dan air, dengan atau tanpa bahan tambahan yang membuat masa padat”. (SNI 03-2847-2002).

Untuk mencapai kualitas/sifat tertentu. Proses pencampuran bahan penyusun beton hingga menjadi beton sangat beragam, salah satunya adalah metode pencampuran beton dengan perbandingan 1:2:3 terhadap volume beton. Yang berarti campuran tersebut menggunakan 1 bagian semen, 2 bagian pasir, dan 3 bagian kerikil. Metode ini sering digunakan terutama dinegara Indonesia ini karena memiliki beberapa keunggulan seperti pengerjaannya yang lebih mudah, peralatan yang digunakan pada pencampuran ini cukup sederhana, dan tidak memerlukan tenaga ahli dan perhitungan rumit dalam perencanaan campurannya.

Beton memiliki kelemahan yaitu lemah terhadap kuat tarik. Kelemahan beton menuntut adanya inovasi dalam pembuatan beton untuk meningkatkan kemampuan beton dalam menahan gaya tarik, karena dengan penambahan baja tulangan beton akan bertambah berat sehingga untuk pembangunan gedung bertingkat perlu dipertimbangkan kembali. Salah satu inovasinya adalah penambahan maupun penggantian agregat halus sebagai salah satu bahan penyusun beton. Pasir merupakan agregat halus yang umumnya digunakan pada campuran beton. Dalam penelitian ini penggunaan pasir sebagai agregat halus akan diganti dengan menggunakan terak.”'Terak ialah hasil sampingan dari pembakaran bijih besi pada tanur tinggi yang didinginkan pelan-pelan di udara terbuka” (Tjokrodimuljo, 2004: III-4). 
Berdasarkan PP Nomor 101

Tahun 2014 tentang Pengelolaan

Limbah Bahan Berbahaya dan

Beracun, terak pengecoran logam termasuk dalam kategori limbah B3. Sehingga jika tidak dilakukan pengelolaan dengan benar akan menimbulkan dampak negatif untuk lingkungan.

Oleh Yahya (2013) pada temu ilmiah IPLBI (Ikatan Peneliti Lingkungan Binaan Indonesia) tentang Pemanfaatan Limbah Industri Baja (Blast Furnace Iron Slag) sebagai Bahan Bangunan, menyimpulkan bahwa pemanfaatan limbah terak aman digunakan sebagai bahan pengganti agregat beton.

Pada penelitian ini terak akan digunakan sebagai bahan pengganti agregat halus (pasir). Berdasarkan hasil penelitian Hariyawan Herlangga (2014) yang telah melakukan uji kimia terak yang berasal dari CV. Salwa Logam Jaya, Desa Batur, Ceper, Klaten ternyata terak memiliki kandungaan Silika dioksida $\left(\mathrm{SiO}_{2}\right)$ sebesar 35,19\%, kandungan kimia ini sangat berpengaruh pada saat proses hidrasi semen. Hal ini memuncullkan ide kepada penulis untuk menggunakan terak sebagai pengganti agregat halus. Tujuan yang hendak dicapai dalam penelitian ini adalah :

- Untuk mengetahui pengaruh terak sebagai pengganti pasir dengan variasi $0 \%, 20 \%, 40 \%, 60 \%, 80 \%$, dan 100\% terhadap kuat tarik beton dengan metode perbandingan 1:2:3.

- Untuk mengetahui apakah berat jenis beton yang dihasilkan masuk dalam kategori berat jenis beton normal.

- Untuk mengetahui besar kuat tarik optimal beton yang dihasilkan dari penggantian terak sebagai pasir dengan variasi $0 \%, 20 \%, 40 \%$, $60 \%$, 80\%, dan 100\% dengan metode perbandingan 1:2:3.

1. Terak (Slag)

Definisi slag dalam ASTM. C.989, "Standard spesification for ground granulated Blast-Furnance Slag for use in concrete and mortar", 
(ASTM, 1995 :494) adalah produk non-metal yang merupakan material berbentuk halus, granular hasil pembakaran yang kemudian didinginkan, misalnya dengan mencelupkannya kedalam air. (Mulyono, 2003: 126)

Menurut Nugraha dan Antoni (2007: 106) "material penyusun slag adalah kapur, silika, dan alumina yang bereaksi pada temperatur $1600^{\circ} \mathrm{C}$ dan berbentuk cairan. Bila cairan ini didinginkan secara lambat maka akan terjadi kristal yang tak berguna sebagai campuran semen dan dapat dipakai sebagai pengganti agregat”.

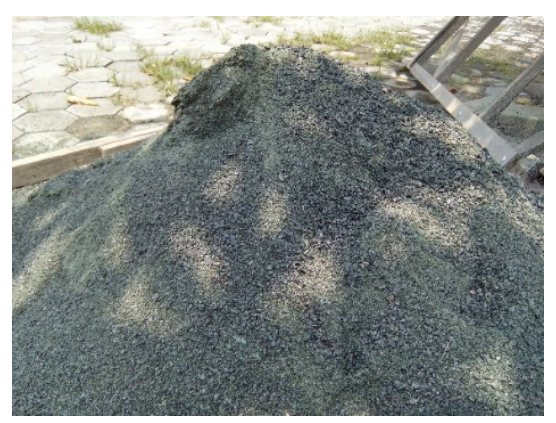

Gambar 1 Terak yang sudah dihaluskan Seperti yang dikemukakan Mulyono (2003: 126) bahwa penggunaan terak memiliki keuntungan yaitu : a) Mempertinggi kekuatan tekan beton karena kecenderungan melambatnya kenaikan kekuatan beton.

b) Menaikkan ratio antara kelenturan dan kuat tekan beton.

c) Mengurangi variasi kekuatan tekan beton.

d) Mempertinggi ketahanan terhadap sulfat air laut.

e) Mengurangi serangan alkalisilika.

f) Mengurangi panas hidrasi dan menurunkan suhu.

g) Memperbaiki penyelesaian akhir dan memberi warna cerah pada beton.

h) Mempertinggi keawetan karena pengaruh perubahan volume.

i) Mengurangi porositas dan serangan klorida.

\section{METODOLOGI PENELITIAN}

Penelitian yang digunakan pada laporan akhir ini menggunakan jenis kuantitatif untuk memberikan suatu gambaran mengenai pengaruh penggantian agregat halus/pasir dengan menggunakan terak yang dihaluskan dengan jumlah variasi persentase tertentu terhadap kuat tarik, dan berat jenis beton dengan metode campuran perbandingan 1:2:3. Gambaran ini dibuat dengan mengadakan eksperimen terhadap sejumlah benda uji untuk 
membandingkan dan mendapatkan jawaban dari tujuan penelitian.

$$
\text { Populasi yang digunakan }
$$

dalam penelitian ini adalah populasi terbatas dimana penelitian dilakukan dengan menggunakan sampel benda uji silinder dengan diameter $150 \mathrm{~mm}$ x $300 \mathrm{~mm}$. Dengan terak sebagai pengganti agregat halus pada campuran beton dengan jumlah variasi persentase tertentu. Sedangkan sampel yang digunakan untuk pengujian kuat tarik dan berat jenis beton 4 sampel dari setiap persentase yang digunakan. Sehingga Jumlah sampel penelitian yang digunakan pada penelitian eksperimen ini berjumlah 24 buah benda uji.

Data yang diperlukan dalam penelitian ini dikelompokkan menjadi dua macam :

1. Data Primer yang diperoleh dari hasil pengujian eksperimen dan pengamatan di laboratorium yaitu melalui pengujian diantaranya :

1) Pengujian untuk semen.

2) Pengujian agregat halus
3) Pengujian terak

4) Pengujian agregat kasar

5) Perhitungan perbandingan $1: 2: 3$

6) Pengujian sampel beton meliputi kuat tarik dan berat jenis.

2. Data sekunder didapat dari literatur/referensi berupa bukubuku relevan yang dapat menunjang penelitian ini.

Data yang digunakan untuk analisis hasil penelitian adalah data primer, sedangkan data sekunder hanya digunakan untuk menunjang analisis data. Data dalam penelitian ini diperoleh dari hasil uji kuat tarik dan berat jenis beton yang merupakan data primer dari penelitian.

\section{Kuat Tarik}

Uji kuat tarik dilakukan dengan memberikan tegangan tarik pada beton secara tidak langsung. Spesimen silinder direbahkan dan ditekan sehingga terjadi tegangan tarik pada beton. Uji ini disebut juga Splitting test atau Brazillian test 
karena metode ini diciptakan di Brazil

(Nugraha \& Antoni, 2007: 262)

Menurut Wang, Salmon, dan hariandja (1993: 11) mengatakan bahwa "kekuatan tarik biasanya ditentukan dengan meggunakan percobaan pembebanan silinder (the split cylinder) menurut ASTM C496 dimana silinder yang ukurannya sama dengan benda uji dalam percobaan tekan diletakkan pada sisinya diatas mesin uji dan beban tekan $\mathrm{P}$ dikerjakan secara merata dalam arah diameter di sepanjang benda uji”.

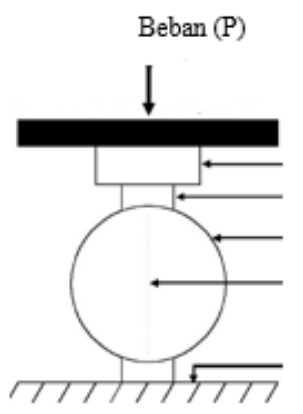

Plat besi tambahan Plywood Silinder $\emptyset 15 \times 30 \mathrm{~cm}$ Zona gagal tarik Plat dasar

Gambar 2. Uji Kuat Tarik

(sumber : Nugraha dan Antoni, 2007:262)

Tegangan tarik dapat dihitung dengan persamaan:

$\mathrm{Ft}=\mathrm{T}=\frac{2 \mathrm{P}}{\pi \mathrm{ld}}$
Dimana :

$$
\begin{array}{ll}
\mathrm{T} & =\text { Kuat tarik beton }(\mathrm{MPa}) \\
\mathrm{P} & =\text { beban hancur }(\mathrm{N}) \\
\mathrm{l} & =\text { panjang spesimen }(\mathrm{mm}) \\
\mathrm{d} & =\text { diameter spesimen }(\mathrm{mm})
\end{array}
$$

\section{Berat Jenis}

Menghitung besarnya berat jenis beton dengan rumus sebagai berikut :

$\mathrm{P}=\mathrm{m} / \mathrm{v}$ Persamaan (2)

Dimana :

$$
\begin{aligned}
& \rho=\text { Berat jenis beton }\left(\mathrm{kg} / \mathrm{m}^{3}\right) \\
& \mathrm{m}=\text { Berat beton }(\mathrm{kg}) \\
& \mathrm{v}=\text { Volume beton }\left(\mathrm{m}^{3}\right)
\end{aligned}
$$

Beton normal yang dibuat dengan menggunakan agregat normal (pasir dan kerikil normal yang memiliki berat jenis antara 2,5 sampai 2,7) mempunyai berat jenis sekitar 2200 sampai dengan $2500 \mathrm{~kg} / \mathrm{m}^{3}$ (SNI 03-2834-2000).

Analisis data yang digunakan dalam penelitian kuantitatif menggunakan statistik. Analisa data yang digunakan untuk mengetahui ada atau tidaknya pengaruh variabel bebas (terak) terhadap variabel terikat 
(kuat tarik beton) dengan metode campuran perbandingan 1:2:3. Namun sebelum menganalisis data diadakan pengujian persyaratan analisis berupa uji normalitas, uji linieritas dan keberartian regresi.

\section{HASIL PENELITIAN DAN}

\section{PEMBAHASAN}

Hasil pengujian kuat tarik, dan berat jenis ditunjukkan pada tabel 1 sebagai berikut:

Tabel 1 Hasil Pengujian Sampel

\begin{tabular}{cccc}
\hline No. & Variasi & $\begin{array}{c}\text { Kuat } \\
\text { Tarik } \\
\text { Rata-Rata } \\
\text { (Mpa) }\end{array}$ & $\begin{array}{c}\text { Berat Jenis } \\
\text { Rata-Rata } \\
\text { (Kg/m } \mathbf{m}^{3}\end{array}$ \\
\hline 1 & $0 \%$ & 4,833 & 2251,795 \\
2 & $20 \%$ & 5,156 & 2306,492 \\
3 & $40 \%$ & 3,989 & 2244,812 \\
4 & $60 \%$ & 5,333 & 2337,834 \\
5 & $80 \%$ & 5,700 & 2294,805 \\
6 & $100 \%$ & 4,444 & 2321,246 \\
\hline
\end{tabular}

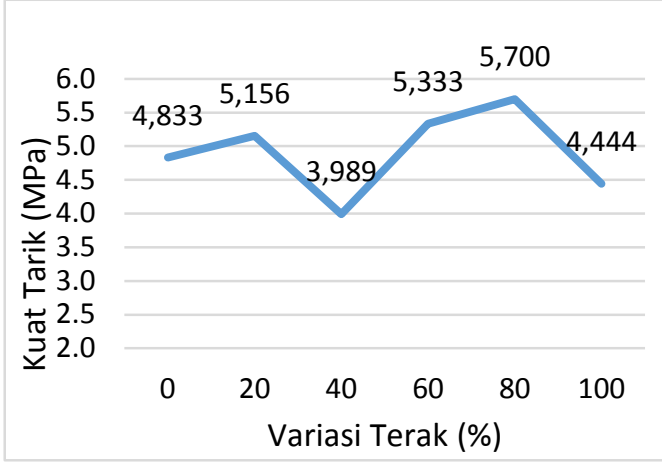

Gambar 3 Hasil Pengujian Kuat Tarik

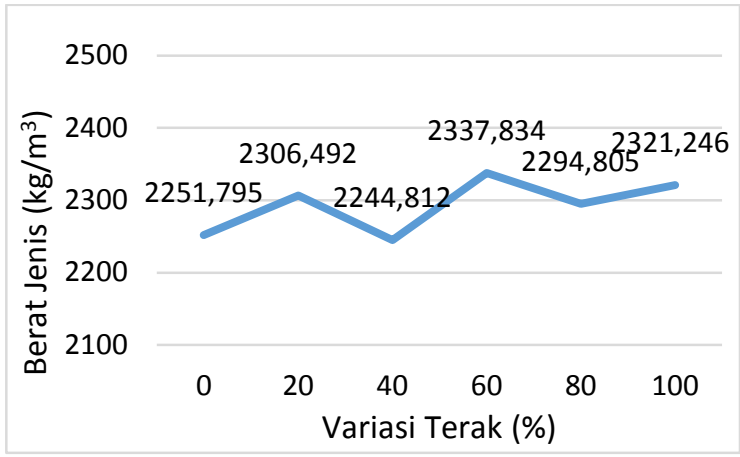

Gambar 4 Hasil Pengujian Berat Jenis

Analisis data menggunakan program komputer Statistical Package for the Social Science (SPSS 16.0) yaitu dengan uji regression (Linear).

Tabel 2. Hasil Pengujian Linieritas

\begin{tabular}{|c|c|c|c|c|c|c|c|c|}
\hline & \multicolumn{5}{|c|}{ Model Summary } & \multicolumn{3}{|c|}{ Parameter Estimates } \\
\hline & $\mathrm{R}$ & & & & & Cons & & \\
\hline Equation & Square & F & dfl & $\mathrm{df2}$ & Sig. & $\tan t$ & bl & b2 \\
\hline Linear & .003 & .067 & 1 & 22 & .799 & 4.835 & .001 & \\
\hline Quadratic & .010 & .109 & 2 & 21 & .897 & 4.731 & .009 & $-7.843 \mathrm{E}-5$ \\
\hline
\end{tabular}

menjelaskan besarnya $\mathrm{R}$ (koefisien korelasi) dan persentase pengaruh variabel bebas terhadap variabel terikat. Hubungan antara variabel bebas (Variasi Persentase terak) dengan variabel terikat (kuat tarik), koefisien korelasinya adalah 0,1 yang berarti tingkat hubungannya sangat 
rendah sesuai dengan ketentuan koefisien korelasi.

Hasil persamaan linier diperoleh hubungan variasi penambahan terak terhadap kuat tarik beton bernilai signifikan sebesar 0,897 > 0,05 dan Fhitung $(0,109)<$ Ftabel $(4,30)$, hal ini menunjukan bahwa Ho diterima sehingga dapat disimpulkan hubungan variasi penambahan terak terhadap kuat tarik beton tidak linier dan regresi tidak berarti.

Hasil berat jenis dapat dilihat pada gambar 5 . berikut ini :

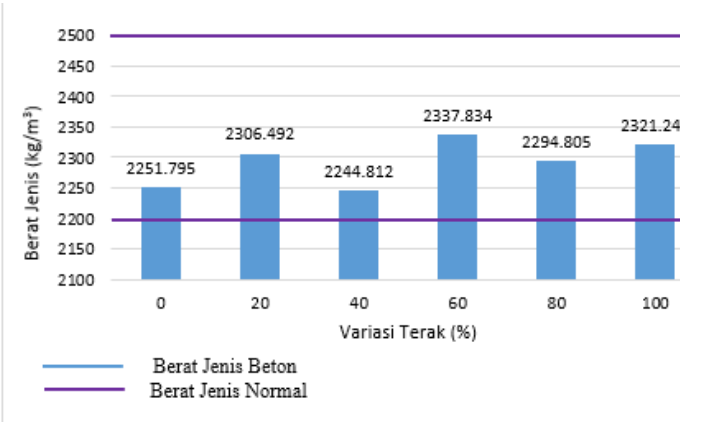

Gambar 5 Diagram Berat Jenis Ratarata

Berdasarkan gambar 5. dapat dilihat semua persentase terak masih menghasilkan berat jenis beton normal dengan berat terendah yaitu pada persentase $40 \%$ sebesar $2244,812 \mathrm{~kg} / \mathrm{m}^{3}$ dan berat tertinggi berada pada variasi 60\% sebesar $2337,834 \mathrm{~kg} / \mathrm{m}^{3}$.

Berdasarkan gambar 3 hasil kuat tarik naik pada variasi penggantian 20\% dan pada variasi $40 \%$ beton mengalami penurunan kekuatan dan naik lagi pada variasi $60 \%$, 80\%, kemudian mengalami penurunan pada variasi $100 \%$. Hal ini terjadi karena pada variasi $40 \%$ pada beberapa sampel beton memiliki banyak rongga yang disebabkan jumlah agregat halus yang dapat mengisi celah semakin sedikit.

Rongga yang ada pada beton sangat berpengaruh terhadap kuat tarik dan berat jenis beton, dilihat pada gambar 3 dan gambar 4 . Kuat tarik beton dan berat jenis beton terendah keduanya berada pada variasi $40 \%$, sedangkan pada variasi $60 \%$ dan $80 \%$ beton yang berongga lebih sedikit dibandingkan variasi $40 \%$ dan variasi $100 \%$. seperti yang ditunjukan yang ditunjukan gambar 6 dibawah ini: 


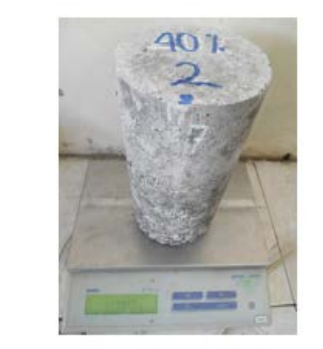

Sampel Variasi $40 \%$

Berat Jenis $\quad=2209,446 \mathrm{~kg} / \mathrm{m}^{3}$ Kuat Tarik $=3,200 \mathrm{MPa}$

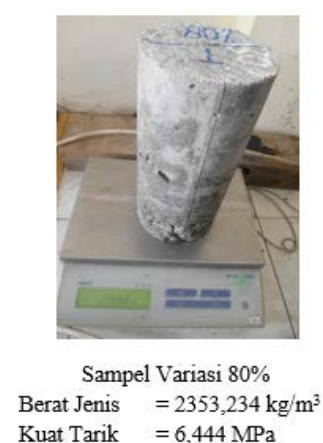

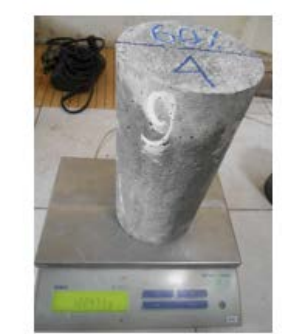

Sampel Variasi $60 \%$ Berat Jenis $=2311,319 \mathrm{~kg} / \mathrm{m}$ Kuat Tarik $=5,556 \mathrm{MPa}$

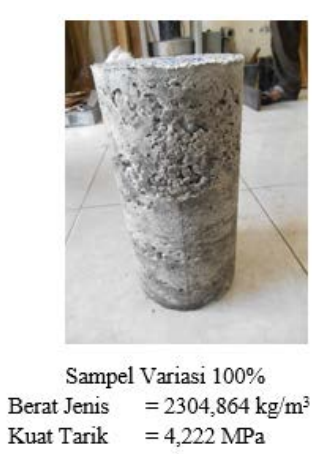

Gambar 6 Perbandingan Berat Jenis dan Kuat Tarik Benda Uji

Nilai kuat tarik beton tidak hanya dipengaruhi oleh kekuatan agregat dari bahan penyusun beton maupun kandungan zat kimianya tetapi juga dipengaruhi oleh beberapa faktor lain. Faktor lain tersebut seperti proses pengerjaan, proses pencampuran agregat, hidrasi semen, ikatan yang terjadi antara pasta semen dengan agregat, proses pemadatan dan tekstur dari agregat halus penyusun beton.

Kandungan kimia yang paling penting dalam proses hidrasi semen adalah $\mathrm{CaO}$ (Kapur) dan $\mathrm{SiO}_{2}$ (Silika) dan terak mengandung kedua senyawa tersebut. Namun karena butiran terak yang kasar dan permukaan terak yang licin sehingga menyebabkan ikatan dengan semen lebih sulit dibandingkan pasir. Semakin tinggi variasi persentase yang digunakan, maka semakin banyak penggunaan terak dan semakin sulit proses pengerjaannya baik dalam proses pencampuran bahan hingga proses pemadatan, sehingga pada beberapa sampel menyebabkan permukaan beton kurang maksimal serta menimbulkan keropos pada beton yang menyebabkan penurunan kuat tariknya.

Berdasarkan SNI 03-2834-2000 berat jenis beton normal berkisar antara $2200 \mathrm{~kg} / \mathrm{m}^{3}$ sampai 2500 $\mathrm{kg} / \mathrm{m}^{3}$. Dapat dilihat pada Gambar 5 bahwa berat jenis terendah pada persentase $40 \%$ yaitu $2244,812 \mathrm{~kg} / \mathrm{m}^{3}$ dan masih masuk dalam kategori beton normal, dan berat tertinggi 
berada pada variasi 60\% sebesar $2337,834 \mathrm{~kg} / \mathrm{m}^{3}$ dan masih masuk kategori berat jenis beton normal. Sehingga dalam penelitian ini semua variasi penggunaan terak dari $0 \%$ 100\% masuk dalam kategori beton normal.

Besar kecilnya berat jenis dapat dipengaruhi beberapa faktor seperti bahan yang digunakan, komposisi bahan dan proses pemadatan beton yang menghasilkan beton padat atau berongga, karena semakin besar rongga yang ada pada beton akan menurunkan berat beton dan berat jenisnya. Besarnya nilai berat jenis diperoleh dari kombinasi bahan penyusun beton terutama agregat halus dan agregat kasar.

\section{KESIMPULAN DAN SARAN}

1. Simpulan

Berdasarkan hasil analisis data dan pembahasan dapat diambil simpulan sebagai berikut :
a. Tidak ada pengaruh antara variasi penggantian terak

sebagai agregat halus terhadap kuat tarik beton atau penggantian terak sebagai agregat halus tidak berpengaruh secara signifikan terhadap kuat tarik beton.

b. Hasil pengujian berat jenis beton dengan variasi penggantian terak $0 \%, 20 \%$, $40 \%$, 60\%, 80\%, dan $100 \%$ termasuk kategori berat jenis beton normal yaitu $2200 \mathrm{~kg} / \mathrm{m}^{3}$ - $2500 \mathrm{~kg} / \mathrm{m}^{3}$. (SNI 03-28342000).

c. Persentase terak optimal sebagai pengganti agregat halus yang menghasilkan kuat tarik beton maksimal terdapat pada persentase penggantian terak 80\% yaitu sebesar 5,700 MPa.

\section{Saran}

Berdasarkan simpulan dan implikasi hasil penelitian, maka dapat dikemukakan saran sebagai berikut :
a. Perlu adany
penelitian pengembangan jika 
menggunakan terak dengan meninjau nilai aspek ekonomis penggunaan terak.

b. Perlu adanya penelitian lanjut tentang penggantian terak dengan penggunaan bahan tambah (admixture).

c. Perlu adanya penelitian lanjut tentang penggantian terak terhadap kuat tarik beton dengan umur beton terak ditentukan.

d. Perlu adanya penelitian lebih lanjut dengan menggunakan metode campuran beton yang berbeda dengan penelitian ini.

e. Perlu adanya pengembangan penelitian lebih lanjut dengan variasi persentase penggunaan terak yang berbeda dengan penelitian ini.

f. Beton terak ini dapat diaplikasikan dilapangan, namun harus lebih diperhatikan saat proses pencampuran dan pemadatan beton, karena beton dengan menggunakan agregat halus berupa terak lebih berat dan lebih kasar dibandingkan dengan menggunakan pasir.

\section{DAFTAR PUSTAKA}

Asroni, A. (2010). Balok dan Pelat Beton Bertulang. Yogyakarta: Graha Ilmu.

Herlangga, Hariyawan. (2014). Pengaruh Penggunaan Terak Sebagai Pengganti Agregat Kasar Terhadap Kuat Tarik dan Berat Jenis Beton Normal Dengan Metode Campuran 1:2:3. Skripsi. Fakultas Keguruan dan Ilmu Pendidikan, Universitas Sebelas Maret.

Mulyono, T. (2003). Teknologi Beton. Yogyakarta: C.V Andi Offset.

Nugraha, P. \& Antoni. (2007). Teknologi Beton dari Material, Pembuatan, ke Beton Kinerja Tinggi. Yogyakarta : C.V Andi Offset. 
Peraturan Pemerintah. (2014). Nomor 101 Tahun 2014: Pengelolaan Limbah Bahan Berbahaya dan Beracun (B3). Presiden Republik Indonesia.

Standar Nasional Indonesia. (2000). SNI 03-2834-2000: Tata Cara Pembuatan Rencana Campuran Beton Normal. Badan Standarisasi Nasional.

Standar Nasional Indonesia. (2002). SNI 03-2847-2002: Tata Cara Perhitungan Struktur Beton Untuk Bangunan Gedung. Badan Standarisasi Nasional.

Tjokrodimuljo, K. (2004). Buku Ajar Teknologi Beton. Yogyakarta : Universitas Gajah Mada.
Wang, C.K., Salmon, C.G., \& Hariandja, B. (1993). Disain Beton Bertulang. Jakarta: Erlangga.

Yahya, M. (2013). Pemanfaatan Limbah Industri Baja (Blast Furnance Iron Slag) sebagai Bahan Bangunan. Makasar : Jurnal Ikatan Peneliti Lingkungan Binaan Indonesia. 